\title{
EFFECT OF PRE-COOLING THE INJECTION SITE ON PAIN PERCEPTION IN PAEDIATRIC DENTISTRY
}

\author{
Shahid Islam, Saqib Rashid, Abu-Bakar Shaikh, Muhammad Ali, Tasleem Hosein, Syed Hussain Askary
}

Fatima Jinnah Dental College \& Hospital, Karachi Pakistan

\begin{abstract}
Objective: To compare the mean Sound, Eye and Motor (SEM) score of pre cooling and topical application at injection site in pediatric patients.

Study Design: A quasi experimental study.

Place and Duration of Study: Fatima Jinnah Dental College and Hospital, Karachi, from Sep to Dec 2017.

Methodology: Sixty four paediatric patients aged between 8-12 who needed dental anaesthesia were randomly divided into two groups A and B. Subjects in group A were applied topical anaesthesia at the injection site for one minute before needle penetration and in group B ice pack was applied for the same duration at the injection site. A designed questionnaire based on SEM scale was used to measure the patients' reaction. Independent-samples $\mathrm{t}$-test was applied to compare the mean SEM score of both groups by taking $p$-value $\leq 0.05$ as significant.

Results: The mean sound, eye and motor (SEM) score was $5.22 \pm 1.718$ for group A and $3.28 \pm 1.373$ for group B; with statistically significant differences between both the groups $(p \leq 0.05)$.

Conclusion: Injection of local anaesthesia at a precooled site results in lesser pain and thus decreased child anxiety levels, more effective analgesia and increased patient comfort.
\end{abstract}

Keywords: Anxiety, Injection, Local anaesthesia, Pain management, Pre cooling.

This is an Open Access article distributed under the terms of the Creative Commons Attribution License (http://creativecommons.org/licenses/by/4.0), which permits unrestricted use, distribution, and reproduction in any medium, provided the original work is properly cited.

\section{INTRODUCTION}

In dentistry, local anaesthesia is used to alleviate pain during painful procedures. It is applied either by infiltration near the procedure site or via regional nerve block. This injection of local anaesthesia is itself fearsome and cause of anxiety for many patients thus being a hindrance in providing appropriate dental care especially to paediatric patients ${ }^{1,2}$. Since paediatric patients are more apprehensive and anxious, they require profound local anaesthesia to ensure pain-free dental treatment and successful behaviour management ${ }^{3}$.

Numerous methods have been used to reduce pain during injection of local anaesthesia. These include application of topical anaesthesia ${ }^{4}$, warming the anaesthetic agent, buffering of local anaesthetic agent ${ }^{5}$, regulating the rate of infiltration $^{6}$, distraction 7 , and vibration of the surrounding tissue ${ }^{8}$. Application of cooling agent has

Correspondence: Dr Shahid Islam, Operative Dentistry, Fatima Jinnah Dental College \& Hospital, Karachi Pakistan

Received: 12 May 2019; revised received: 10 Oct 2019; accepted: 30 Oct 2019 been employed for pain relief in numerous medical conditions including fractures, bruises, sprains and sports injuries 9,10 , Literature also suggests precooling to be useful for the relief of postoperative pain and edema ${ }^{11,12}$.

There have been few studies on the effect of precooling in reducing the pricking pain of the injection. Aminabadi et al. compared precooling with topical anaesthesia in children aged 5-6 years, to assess the pain caused by local anaesthesia injection. They found precooling to be more effective in decreasing the pain ${ }^{13}$. Ghaderi et al, applied topical anaesthesia on one side and topical anaesthetic plus ice on the other side to compare the effect in paediatric patients. They found significantly lesser pain perception due to infiltration on the precooling side ${ }^{14}$. Bhadauria et $a l$, used the same method in adult patients aged between 31-60 years and found lower pain on the precooling side as compared to the side where only topical anaesthesia was applied ${ }^{15}$. Mohiuddin et al, also had similar results when comparing pre-cooling with local anesthetic gel before 
infiltration in paediatric patients requiring extractions in maxillary teeth ${ }^{16}$.

The aim of this study was to compare the effect of precooling and topical anaesthesia application at the infiltration site before injection in paediatric patients. If it is found to have a superior outcome, effective precooling can lead to decreased child anxiety levels, more effective analgesia and increased patient comfort at a lesser cost with minimal chances of allergic reactions related to topical anaesthetic, thus more acceptability on part of the paediatric patient and the dentist.

\section{METHODOLOGY}

This study was conducted in Fatima Jinnah Dental College and Hospital (FJDC \& H), Karachi from September to December 2017. Non-probability consecutive sampling was used to collect data from 64 subjects aged between 8-12 years who visited the Paediatric dentistry department of FJDC \& $\mathrm{H}$ for dental treatment, mostly extractions, requiring dental anaesthesia injection. Considering previously reported means ${ }^{14}$, WHO calculator was used to collect sample size at $95 \%$ confidence interval. Whole procedure was explained and consent was taken in written as well as informed to parents/guardians. Institutional Ethics Committee approved all the steps of this study process by issuing the certificate number MAR-2018-OPR02.

Comprehensive history was taken before including the subject in the study. Patients with history of psychiatric disorders, fear of needles and dental abscess or fistula at the procedure site were ruled out as participants for the study. Only those subjects who were cooperative, were able to follow instructions, and had no known allergy to the materials being used, no past unpleasant dental experience and no history of pain secondary to pulpitis were included in the study.

Subjects were randomly assigned into 2 equal groups A and B. Sealed envelope method was used to randomise the two groups. Envelopes of same size and colour were placed in a box having labels A and B. Patients were asked to pick one envelope and open it to show the label.

After explaining the procedure, Topical anaesthesia Benzocaine gel 20\% (BENZO-JEL, Henry Schein Inc., USA) was applied to group " $\mathrm{A}$ " over dried mucosa at the injection site for 1 minute using a cotton applicator. Patients in group " $\mathrm{B}$ " were applied an ice pack for 1 minute at the injection site. Ice pack was made by filling the finger of a latex glove with water, tying it and placing it in the freezer at $0-4^{\circ} \mathrm{C}$. This was followed by the infiltration of local anaesthesia Lidocaine 1:100, 000 (Medicaine, Huons Co. Ltd., Korea) using 27gauge needle (Hakusui Trading Company Limited, Japan) to both the groups. Needle was slightly bent at 5-6 mm to make sure uniform depth of needle penetrated the site in all the subjects. The operator marked the recordings on the designed questionnaire based on SEM scale.

The parameters judged in SEM scale (table-I) include the sound, eye signs and body movements of the patient during the application of injection containing local anaesthesia. The SEM scale scores the patient's reaction as "no response" (0), "mild discomfort" (1), "moderately painful" (2) and "Severe pain" (3).

Data was analysed using Statistical Packages for Social Sciences (SPSS) version 23. Normality testing was done using Shapiro-Wilk test and data was found to be normally distributed. Chisquare test was used to check the association between the variables and the Independent-Samples t-test was applied to compare the mean SEM scores of both groups by considering $p$-value $\leq 0.05$ as significant.

\section{RESULTS}

The study constituted of 64 subjects, 27 (42\%) females and $37(58 \%)$ males, with mean age of $9.68 \pm 1.41$ years. After statistical analysis, Mean \pm SD score was found to be statistically different in total SUM of score as well as sound, eye and motor parameters individually $(p \leq 0.05)$ (table-II). There was no statistically significant difference between the two groups in terms of age (Indepen- 
dent t-test, $p=0.103$ ) or sex (Fisher's Exact test, $p=0.73$ ).

The Mean \pm SD values are presented in tableII. Group 'A' was reported to have a painful reaction according to the SEM scale for all three components (sounds, eye, and motor) whereas group ' $B$ 'observed lesser pain reaction.

Table-III represent the SEM scale findings. According to the mean SEM score for all three components (sound, eye, and motor) related with gender, the results show that 'Severe pain' occurs mostly in cases of topical anaesthesia only, for both male and female groups. better patient cooperation at the time of injection administration prior to extraction of primary teeth, as evaluated by SEM score analysis.

The results of this study are in line with the study carried out by Ghaderi ${ }^{14}$, that demonstrated outcomes of pain perception to local anaesthesia injection post-application of topical anaesthesia with and without pre-cooling the injection site in 50 paediatric patients. Their mean (SEM) scores were $4.06 \pm 1.32$ and $5.44 \pm 1.79$ for the study and control groups, respectively; with statistically significant difference $(p<0.05)$ between the two groups. However in the present study, topical anaesthesia was applied to only one group so

Table-I: Sem scale for assessment of children behaviour ${ }^{14}$.

\begin{tabular}{|c|c|c|c|c|}
\hline Parameter & Comfort & Mid Discomfort & Moderated Discomfort & Severe Discomfort \\
\hline Sound & No sound & $\begin{array}{l}\text { Non specific sound } \\
\text { (probable pain) }\end{array}$ & $\begin{array}{l}\text { Verval complaint, louder } \\
\text { sound }\end{array}$ & $\begin{array}{l}\text { Verval complaint, } \\
\text { shoutin, crying }\end{array}$ \\
\hline Eye & No sign & $\begin{array}{l}\text { Dilated eyes without tears } \\
\text { (anxiety sign) }\end{array}$ & $\begin{array}{l}\text { Tears, sudden eye } \\
\text { movements }\end{array}$ & Crying \\
\hline Motor & $\begin{array}{l}\text { Relaxed body } \\
\text { and hand status }\end{array}$ & $\begin{array}{l}\text { Muscular contraction, } \\
\text { contraction of hand }\end{array}$ & $\begin{array}{l}\text { Sudden body and hand } \\
\text { movements }\end{array}$ & $\begin{array}{l}\text { Hand movements for } \\
\text { defense }\end{array}$ \\
\hline \multicolumn{5}{|c|}{ Table-II: Mean sem (sound, eye and motor) scores of both groups. } \\
\hline \multicolumn{2}{|c|}{ Parameter } & Group A (Topical) & Group B (Precooling) & \multirow{2}{*}{$p$-value } \\
\hline \multicolumn{2}{|l|}{ n } & 32 & 32 & \\
\hline \multicolumn{2}{|c|}{ Sound (Mean \pm SD) } & $1.78 \pm 0.70$ & $1.16 \pm 0.62$ & $<0.01$ \\
\hline \multicolumn{2}{|c|}{ Eye (Mean \pm SD) } & $1.88 \pm 0.66$ & $1.19 \pm 0.59$ & $<0.01$ \\
\hline \multicolumn{2}{|c|}{ Motor $($ Mean \pm SD) } & $1.59 \pm 0.71$ & $0.94 \pm 0.56$ & $<0.01$ \\
\hline \multicolumn{2}{|c|}{ SUM of Scores (Mean \pm SD) } & $5.22 \pm 1.71$ & $3.28 \pm 1.37$ & $<0.01$ \\
\hline
\end{tabular}

Table-III: Groups related with gender and patient response.

\begin{tabular}{l|c|c|c|c|c|c}
\hline \multirow{2}{*}{ Groups } & \multirow{2}{*}{ Gender } & \multicolumn{4}{|c}{ Patients Response } & \multicolumn{2}{c}{$\boldsymbol{p}$-value } \\
\cline { 3 - 6 } & & No Pain & Mild Pain & Moderate & Severe Pain & $2(11.2 \%)$ \\
\multirow{2}{*}{ Topical } & Male $(\mathrm{n}=18)$ & - & $7(38.8 \%)$ & $9(50 \%)$ & $2(14.2 \%)$ \\
\cline { 2 - 6 } & Female $(\mathrm{n}=14)$ & - & $6(42.8 \%)$ & $6(42.8 \%)$ & - \\
\multirow{2}{*}{ Precooling } & Male $(\mathrm{n}=19)$ & $3(15.7 \%)$ & $12(63.1 \%)$ & $4(21 \%)$ & - \\
\cline { 2 - 6 } & Female $(\mathrm{n}=13)$ & - & $11(84.6 \%)$ & $2(15.4 \%)$ & - \\
\hline
\end{tabular}

\section{DISCUSSION}

This clinical trial was aimed to evaluate and comparethe response to pain perception of paediatric patients by cooling the injection site or application of topical anaesthetic gel before the administration of local anaesthesia injection for extraction of any primary tooth.

Results of this study indicated that precooling of the injection site at $0-4^{\circ} \mathrm{C}$ for 60 seconds with an ice-pack resulted in decreased pain and as to compare its effect with pre-cooling.

Results of this study are also similar to the study conducted by Chan et al17. They used laser system with an added cooling device to treat 37 patients with nevus of Ota removal. The postoperative pain after laser therapy was more severe for the non-cooled side (pain score: 3.91) than the cooled side (pain score: 2.97). However their results were not statistically significant and the criteria used to objectify pain was not specified. Also, there must be a difference in the nat- 
ure and severity of pain induced by laser as compared to injection of local anaesthesia. Mahshidfar et al, also found pre-cooling to be effective in decreasing the pain of local anaesthesia in patients presenting with lacerations in emergency department ${ }^{18}$. Harbert also demonstrated in his study that application of ice to injection site, hard palate, results in decreased pain perception ${ }^{19}$. However, he did not carry out a randomized clinical trial nor was he able to put his result into an objective pain scoring system. Aminabadi concluded that 2 min application of ice before injecting for a nerve block results in reduced pain sensations $(p<0.05)^{13}$.

A study done by Hameed et al. using tetrafluoroethane as a pre-cooling agent on children before injections also had similar results with precooling being more effective than topical spray, but the results were statistically insignificant $(p>0.05)^{20}$. However there is a certain disadvantage of using tetrafluorethane as using it for more than $10 \mathrm{sec}$ appears to make injuries to the oral mucosa ${ }^{21}$.

Aminah et al, compared the effect of various desensitizing techniques such as application of topical anesthesia, vibration, pre-cooling and buffering of the anesthetic agent in decreasing pain among pediatric patients ${ }^{22}$. They found lowest pain score in precooling group (mean pain score: 2.4) followed by vibration group (mean score: 2.6). Topical anesthesia group had the highest pain score (6.2).

However, none of the above studies mentioned the penetration depth of the needle which might result in variation in the level of pain. In this study, needle was bent at 5-6 mm during all applications so as to ensure uniform depth of penetration, thus similar painful stimulus.

Numerous validations have been postulated to provide an explanation for the outcome of local analgesia on injuries. Reduction in edema is brought about by decreased tissue metabolic rate and vasoconstriction. This explains the potential analgesic properties of ice when it is used as topical analgesic agent to relieve bruising, blee- ding and edema related to sports injuries and as pain management post orthopaedic surgery ${ }^{9,23}$. Cryoanalgesia is thought to relieve pain by slowing or retarding pain signalling and neuromuscular transmission ${ }^{24}$. It is also thought to bring about a reduction in the muscle tone by reducing the activity of muscle spindles ${ }^{25}$. Another suggested pathway by which cold application reduces pain perception and increases pain threshold is, stimulation of myelinated A-fibres that in turn activate inhibitory pain pathways. It is also thought to bring about its effects at the level of spine which prevents stretch reflex and moderates muscle spasm ${ }^{23}$. This study highlights the increase in pain threshold that is brought about by the application of topical cooling in response to local stimuli like needle-pricks. Reduced pain results in less anxiety and improved patient management.

\section{STUDY LIMITATIONS}

However this study had its limitations. Due to limited number of paediatric patients that required multiple extractions, the same patient could not be taken as the case and control. Also present study was conducted in a dental hospital that is flooded with patients therefore blinding could not be carried out due to manpower constraint. Hence operator assessed the patient response on the basis of SEM scale himself which might have led to some bias in the results.

\section{ACKNOWLEDGEMENTS}

The authors would like to thank all the participants for their time and cooperation. The authors deny any conflicts of interest.

\section{CONCLUSION}

Site pre-cooling proves itself to be an inexpensive and effective method of minimizing pain to stimuli like needle-stick insertions, especially in paediatric patients. It also results in reduced anxiety, better patient management and promising continued dental treatment of the paediatric patient.

\section{CONFLICT OF INTEREST}

This study has no conflict of interest to be declared by any author. 


\section{REFERENCES}

1. Chandrasekaran J, Prabu D, Sunayana M, Ahmed A, Kumarasamy B. Efficacy of painless injection technique-vibraject-clinical trial in chennai, India. Inter J Med Dental Sci 2014; 3(1): 250-56.

2. Mc Donald RE, Avery DR, Dean JA. Mc Donald and avery's dentistry for the child and adolescent. 9th ed. Maryland Heights: Mosby/Elsevier; 2011 [Internet]. https://www. elsevier.com/ books/mcdonald-and-avery-dentistry-for-the-child-andadolescent/ 9780323057240.

3. Veneva ER, Belcheva AB. Local anesthesia in pediatric patientsa review of current and alternative methods, devices and techniques. Folia Medica. 2018; 60(3): 381-88.

4. Lee HS. Recent advances in topical anesthesia. J Dent Anesth Pain Med 2016; 16(4): 237-44.

5. Kurien RS, Goswami M. Comparative evaluation of anesthetic efficacy of warm, buffered and conventional $2 \%$ lignocaine for the success of inferior alveolar nerve block (IANB) in mandibular primary molars: A randomized controlled clinical trial. J Dent Res Dent Clin Dent Prospects 2018; 12(2): 102-05.

6. Kanaa MD, Meechan JG, Corbett IP, Whitworth JM. Speed of injection influences efficacy of inferior alveolar nerve blocks: A double-blind randomized controlled trial in volunteers. J Endod 2006; 32(1): 919-23.

7. Salati SA. Minimizing the pain in local anesthesia injection-A review. J Pak Associat Dermatol 2016; 26(2): 138-42.

8. Shilpapriya M, Jayanthi M, Reddy VN, Sakthivel R, Selvaraju G, Vijayakumar P. Effectiveness of new vibration delivery system on pain associated with injection of local anesthesia in children. J Ind Soc Pedod Prev Dent 2015; 33(3): 173-75.

9. Meeusen R, Lievens P. The use of cryotherapy in sports injuries. Sports Med 1986; 3(6): 398-14.

10. Galiuto L. The use of cryotherapy in acute sports injuries. Ann Sports Med Res 2016; 3(2): 1060-64.

11. Malanga GA, Yan N, Stark J. Mechanisms and efficacy of heat and cold therapies for musculoskeletal injury. Postgrad Med 2015; 127(1): 57-65.

12. Block JE. Cold and compression in the management of musculoskeletal injuries and orthopedic operative procedures: a narrative review. Open Access J Sports Med 2010; 1(1): 105-08.

13. Aminabadi NA, Farahani RM. The effect of pre-cooling the injection site on pediatric pain perception during the administration of local anesthesia. J Contemp Dent Pract 2009; 10(3): 43-50.

14. Ghaderi F, Banakar S, Rostami S. Effect of pre-cooling injection site on pain perception in pediatricdentistry: a randomized clinical trial. Dental Res J 2013; 10(6): 790-94.

15. Bhadauria US, Dasar PL, Sandesh N, Mishra P, Godha S. Effect of injection site pre-cooling on pain perception in patients attending a dental camp at Life Line Express: A split mouth interventional study.Clujul Med 2017; 90(2): 220-23.

16. Mohiuddin I, Setty JV, Srinivasan I, Desai JA. Topical application of local anaesthetic gel vs ice in pediatric patients for infiltration anaesthesia. J Evolut Med Dent Sci 2015; 4(74): 12934-41.

17. Chan HHL, Lam Lk, Wong DSY, Wei WI. Role of skin cooling in improving patient tolerability of $\mathrm{Q}$ switched Alexandrite (QS Alex) laser in nevus of Ota treatment. Lasers Surg Med 2003; 32(2): 148-51.

18. Mahshidfar B, Shevi SC, Abbasi M, Kasnavieh MH, Rezai M, Zavereh $\mathrm{M}$, et al. Ice reduces needle-stick pain associated with local anesthetic injection. Anesth Pain Med 2016; 6(5): e38293-99.

19. Harbert H. Topical ice: a precursor to palatal injections. J Endod 1989; 15(1): 27-28.

20. Hameed NN, Sargod SS, Bhat SS, Hegde SK, Bava MM. Effectiveness of precooling the injection site using tetrafluorethane on pain perception in children. J Ind Soci Pedodont Prevent Dentist 2018; 36(3): 296-98.

21. Wiswall AT, Bowles WR, Lunos S, Mc Clanahan SB, Harris S. Palatal anesthesia: Comparison of four techniques for decreasing injection discomfort. Northwest Dent 2014; 93(4): 25-29.

22. Aminah M, Priya N, Parul S, Monali B. Comparison of topical anesthetic gel, pre-cooling, vibration and buffered local anesthesia on the pain perception of pediatric patients during the administration of local anesthesia in routine dental procedures. Inter J Contemp Med Res 2017; 4(2): 400-03.

23. Daniel DM, Stone ML, Arendt DL. The effect of cold therapy on pain, swelling, and range of motion after anterior cruciate ligament reconstructive surgery. Arthroscopy: J Arthroscopic \& Relat Surg 1994; 10(5): 530-33.

24. Halar EM, DeLisa JA, Brozovich FV. Nerve conduction velocity. Relationship of skin, subcutaneous and intramuscular temperatures. Arch Physical Med Rehabilitat 1980; 61(5): 199-03.

25. Brasileiro JS, Faria AF, Queiroz LL. Influence of local cooling and warming on the flexibility of the hamstring muscles. Brazil J Physical Therapy 2007; 11(1): 57-61. 